\title{
Waist circumference compared with other obesity parameters as a determinant of coronary artery disease in essential hypertension: from statistics to clinical practice
}

\author{
Hypertension Research (2017) 40, 517; doi:10.1038/hr.2016.172; published online 8 December 2016
}

We would like to thank Ayubi et al. ${ }^{1}$ for their interest in our work. ${ }^{2}$ As suggested, we fully agree that for clinical prediction there are diverse tools for model building and risk assessment. $^{3}$

In this paper, event-free survival analysis was performed using the Kaplan-Meier method to plot the cumulative incidence of end points, and groups were compared using the Mantel log-rank test. Additionally, Cox proportional hazard analysis was used to examine associations between the studied risk factors and the cumulative incidence of coronary artery disease (CAD). These effects, expressed as hazard ratios and 95\% confidence intervals, were based on Cox regression models, in line with previous publications. ${ }^{4,5}$

The results of this 6-year follow-up study of 2266 hypertensive patients underscore the relationship of all obesity parameters with $\mathrm{CAD}$ incidence in the univariate models. However, in three different multivariate Cox regression models that included established risk factors for $\mathrm{CAD}$, waist circumference, but not body mass index or waist-to-hip ratio, was independently related to $\mathrm{CAD}$ in our population. $^{2}$ Using the suggested guidelines ${ }^{6}$ for cut-off values for waist circumference measurement, we reanalyzed our data using a ROC curve; however, this did not provide any additional clinical implication.

In conclusion, the association of increased waist circumference with the incidence of $\mathrm{CAD}$ is independent of age, gender, metabolic status, renal function and left ventricular mass-related pathways of atherosclerotic disease progression. ${ }^{2}$ This finding strengthens the importance of waist circumference measurement in everyday clinical practice in hypertension.

\section{CONFLICT OF INTEREST}

The authors declare no conflict of interest.

Kyriakos Dimitriadis, Costas Tsioufis and Dimitris Tousoulis

First Cardiology Clinic, National and Kapodistrian University of Athens, Hippokration Hospital, Athens, Greece E-mail:ktsioufis@hippocratio.gr

1 Ayubi E, Sani M, Khazaei S, Safiri S. Waist circumference compared with other obesity parameters as determinants of coronary artery disease in essential hypertension: statistical issues to avoid misinterpretation. Hypertens Res 2017; 40: 516.
2 Dimitriadis K, Tsioufis C, Mazaraki A, Liatakis I, Koutra E, Kordalis A, Kasiakogias A, Flessas D, Tentolouris N, Tousoulis D. Waist circumference compared with other obesity parameters as determinants of coronary artery disease in essential hypertension: a 6year follow-up study. Hypertens Res 2016; 39: 475-479.

3 DeLong ER, DeLong DM, Clarke-Pearson DL. Comparing the areas under two or more correlated receiver operating characteristic curves: a non-parametric approach. Biometrics 1988, 837-884

4 Tsioufis C, Vezali E, Tsiachris D, Dimitriadis K, Taxiarchou E, Chatzis D, Thomopoulos C, Syrseloudis D, Stefanadi E, Mihas C, Katsi V, Papademetriou V, Stefanadis C. Left ventricular hypertrophy versus chronic kidney disease as predictors of cardiovascular events in hypertension: a Greek 6-year-follow-up study. $J$ Hypertens 2009; 27: 744-752.

5 Georgiopoulos G, Tsioufis C, Tsiachris D, Dimitriadis K, Kasiakogias A, Lagiou F, Andrikou E, loannidis I, Hatziagelaki E, Tousoulis D. Metabolic syndrome, independent of its components, affects adversely cardiovascular morbidity in essential hypertensives. Atherosclerosis 2016; 244: 66-72.

6 Mancia G, Fagard R, Narkiewicz K, Redon J, Zanchetti A, Böhm M, Böhm M, Christiaens T, Cifkova R, De Backer G, Dominiczak A, Galderisi M, Grobbee DE, Jaarsma $\mathrm{T}$, Kirchhof $\mathrm{P}$, Kjeldsen SE, Laurent $\mathrm{S}$, Manolis AJ, Nilsson PM, Ruilope LM, Schmieder RE, Sirnes PA, Sleight $P$, Viigimaa $M$, Waeber B, Zannad F. Task Force for the Management of Arterial Hypertension of the European Society of Hypertension and the European Society of Cardiology. 2013 ESH/ESC Guidelines for the management of arterial hypertension: the Task Force for the management of arterial hypertension of the European Society of Hypertension (ESH) and of the European Society of Cardiology (ESC). Eur Heart J 2013; 34: 2159-2219. 